The Social Sciences 14 (4): 155-168, 2019

ISSN: $1818-5800$

(C) Medwell Journals, 2019

\title{
External and Internal Factors Affecting Student's Academic Performance
}

\author{
Thssan Abdulkadhum Jabor AL-Muslimawi and Azhar Adhiem Hamid \\ University of Kufa, Najaf, Iraq \\ ihssana.almuslimawi@uokufa.edu.iq
}

\begin{abstract}
This study was conducted to examine factors influencing academic performance of students. The measured factors have been divided into: external factors (Extracurricular activities, family problems, work and financial, social and other problems) and internal factors (student's competence and aptitude, class: schedule, size, environment, text books and exam systems, learning facilities and technology). Eighty students, (40 males and 40 females) from all stages in the English Department, College of Arts, University of Kufa have been subjected in a survey by using a questionnaire for information gathering about different factors relating to their academic performance. The factors are gauged by the student's answers. The data of questionnaire have been analyzed by many statistical methods (Microsoft Excel program, ANOVA and Histograms). The results of the study reveal that students are suffering from outdated text books and routine exam systems align with family problems. The test also shows that the majority of students have a great zeal towards the systematic application of knowledge in classroom through technological facilities, males are more eager in this aspect. A deeper analysis displays that the age between $20-23$ is more acceptable of this application than the others.
\end{abstract}

Key words: Student's problems, academic performance, learning facilities, family problems, deeper analysis, text books and exam systems

\section{INTRODUCTION}

Measuring of academic performance of learners is challenging as student's performance is a result of socio-economic, psychological and environmental factors. Education is growing as a profitable industry with prime goal to produce high quality education which delivers well-educated and skillful students because institutions are valueless without quality students.

Grade Point Averages (GPA) represent student's academic accomplishments. A good average is useful for students who are seeking further education or decent jobs while low average can crash their hopes and careers. This research is set to detect the most effective factors on student's academic performance. This research would contribute to find out the problems which are responsible for student's inelastic behavior towards study, along with identifying those factors which would fundamentally help learners to recognize and focus on their weaknesses and to overcome their flaws.

College years play an important role in developing one's own character. Character is defined as: the particular combination of qualities that makes them different from others (Cambridge English Dictionary). During college times, the five domains of beliefs: trust, safety, power, esteem and intimacy (Cognitive behavioral theory, Antoniou (1998) are firmly merging with each other. Every single student experiences a set of positive and negative feelings during college years. Most of the time, students will seek a source of support which families have the biggest part concerning this support (Brown and Kurpius, 1997).

This research is divided into four sections. The first section introduces a general introduction about the factors that may have an influence on student's academic performance and the purpose of the study. Section two presents the literature review where the factors are given. Section three demonstrates the methodology of the research, research design, participants and data analysis while section four provides the conclusion as well as suggestions for further work.

Statement of the problem: Academic performance which is measured by examination results is one of primary aims of a university. Hoyle exhorted that universities are established with the priority of imparting knowledge and skills to those who go through them. Universities whose vision is to be a center of excellence in the heart of education system are competing with one another for the sake of having a better ranking, therefore, they have noted that while some students perform high others do not. As a result, they are concerned about those who do

Corresponding Author: Ihssan Abdulkadhum Jabor AL-Muslimawi, University of Kufa, Najaf, Iraq, ihssana.almuslimawi@uokufa.edu.iq 
not do well because if this poor performance go unnoticed, universities might risk losing their reputation being amongst the finest institutions in the world. Hence, in this research, the researcher tries to stand on the factors that may affect student's academic performance in the Department of English, College of Arts, University of Kufa. Consequently, results can be generalized to all departments of English in the university as they have almost the same educational and environmental background.

Purpose of the study: The purpose of this study is to determine which factors are having the greatest influence on student's academic performance and to provide a better understanding of what is going on in a student's mind.

Specific objectives: To point out the mutual effect between external classroom factors and academic performance of undergraduate students. To point out the mutual effect between internal classroom factors and academic performance of undergraduate students.

\section{Research questions:}

- What are the external factors that heavily affect student's academic performance of EFL learners?

- What are the internal factors that may more affect student's academic performance of EFL learners?

Significance of the study: This study can be of considerable value from a practical and theoretical point of view. Theoretically, it is hoped that researchers in the field of linguistics will derive the benefit of its theoretical issues. Publishers and text analysts could take the results of this study into consideration. Finally, it will help English teachers as well as learners to understand the common features of the factors affecting student's academic performance and assist them in overcoming some of the difficulties encountered in this area.

\section{Operational glossary}

Competence: Competence in Chomsky's sense is defined as the system of rules that governs an individual's tacit understanding of what is acceptable and what is not in the language they speak.

External: Outside influences that can impact student's academic performance.
Internal: Influences within the class that can impact student's academic performance.

Extracurricular: An activity that is not part of the usual college subject.

Literature review: Educational services are not tangible and are difficult to measure because they result in the form of transformation of knowledge, life skills and behavioral modification of learners (Tsinidou et al., 2010). So, there is no generally agreed upon definition of quality that is applied to education scope. The definition varies from culture to culture (Michael, 1998). The environment and the personal characteristics of learners play an important role in their academic success. The school personnel, members of families and communities can also provide an appreciated help and support to students for the quality of their academic performance. This social assistance has a crucial factor in the achievement of academic aims (Goddard, 2003). Besides the social structure, parent's involvements in their family member's education increase the rate of their success (Furstenberg and Hughes, 1995).

Above the demographic factors, the influences of SES (Socio-Economic Status) are still diffused at the individual level. The SES can be deliberated in many ways, calculated by the parental education, occupation, income and facilities used by individuals separately or collectively. Parental education and family SES level have a positive relation with the student's quality of achievement (Caldas and Bankston, 1997; Parelius and Parelius, 1987). The students with high level of SES perform better than those with lower SES (Kirkup, 2008).

The accomplishment of students is negatively correlated with the low SES of their parents because it prevents the individual from gaining access to sources and resources of learning (Duke, 2000). It is also observed that the economically disadvantaged parents are less able to afford the cost of education of their sons and daughters at higher levels and consequently they do not work at their fullest potential (Rouse and Barrow, 2006). Fantuzzo et al. (2000) concluded that students whose parents are educated score higher on standardized test than those whose parents are less educated. The reason beyond it that educated parents can better communicate with their sons and daughters regarding the university work, activities and the information that have been taught. So, educated parents can better assist them with their course of study. 
Theory of educational productivity by determined three groups of nine factors based on affective, cognitive and behavioral skills for optimization of learning that affect the quality of academic outcome: aptitude (ability, development and motivation), instruction (quantity and quality), environment (home, class, peers and lecturers) (Roberts, 2007). There are two types of factors: first, the external factors that include:

- Extracurricular academic activities

- Family problems

- Work and financial situation

- Social and other problems

Second, the internal factors that include:

- Student's competence and aptitude

- Class: schedule, size, environment

- Text books and exam systems

- Learning facilities and technology

\section{External factors}

Extracurricular academic factors: A healthy balance of academic and extracurricular activities is a key to a successful college experience. An imbalance causes poor performance in one area but it can lead to stress and anxiety in both. University students engage in a variety of co-activities these can be sports, debate, drama, university publications, student council and many others. Mostly, these activities are voluntary and students are not expected to get paid or get grades. Many extracurricular activities have proven to be useful in developing academic efficacy, despite that they are not directly related to academic subjects. Students taking part in co-activities did better academically than those who did not.

Extracurricular activities help students to demonstrate their drive, focus and passion in addition, they show the ability of students to effectively communicate their ideas and voice their opinions. These qualities matter to college because college students should and are expected to be independent in designing and keeping up with their course of study than high schoolers. Generally, colleges do not really want homogeneous population. They request students to be interested in multi different things, so that, academic and extracurricular life on campus thrive as by Roberts (2007)

Work and financial situation: Zest is not an ample supply, since, work and finances are having a great impact on student's academic experience as stated in UCE's Center for Research into Quality (CRQ). As from a country that suffers from the recession in addition, to tuition and life expenses continue to rise, a lot of students are under heavy pressure to make ends-meet. For some students it is at the cost of their academic pursuit. National Survey of Students Engagement (NSSE) in 2012 asked how finances were effective on student's academic activity. The results are as follows: $60 \%$ of full-time seniors who are having more than $80 \mathrm{~h}$ work per month said it interfered with their academic performance. A group of, $32 \%$ of fresh students and $36 \%$ of seniors also indicated that financial concerns interrupted their academic achievement. Besides, $27 \%$ of first-year students and $34 \%$ of seniors said they "Often" or "Very often" chose not to purchase required academic materials. This proves that work and financial concerns endanger student's performance at universities.

Family problems: Hagridden diverse problems that families experience such as unfaithfulness, violence and separation are having a strong negative impact on students academic performance. These problems experienced in families are having negative impact on members of the family. Students who have tested family problems deal with wide range of issues during their college years such as the inability to manage conflict between roommates, challenging relationship with friends and troubles inside the class. These are results from the fact that they learn from their parents how to react towards a problem, disagreement or anger. They will try to imply the same tactics used by their parents and this would lead to even worse troubles that would firmly affect their psychology and drive them away from being attentive in classes and distract their focus from only on study to endlessly repeated problems. Billingham and Notebaert (1993) declared that family members often react compulsively in an attempt to avoid repeating the same actions by their parents. This rarely leads to a progress in dealing with the conflict-filled situation (Fagan and Rector, 2000).

Social and emotional problems: Personal factors, like instincts and emotions and social factors such as cooperation rivalry are directly related to a complex psychology of motivation. It is a recognized fact that the various responses of the individuals to various kinds of stimuli are determined by a wide variety of tendencies. Some of these innate tendencies are constructive while others are harmful. For some reason, a student may have developed a dislike for some subjects because they may fail to observe its value or may lack foundation. This dislike results in a bad emotional state. Social discontent springs from the knowledge or delusion that one is below others in welfare. 


\section{Internal classroom factors}

Student's competence and aptitude: Competence is a set of defined behaviors that provide a structured guide enabling the identification, evaluation and development of individual students (White and White, 1995). A research by Harb and El-Shaarwi (2006) found that the most important factor with positive influence on student's performance is student's competence in English language. If the student has a strong grip on English, it will heighten their communication skills and enhance their academic output it will even encourage them to take turns in presentations.

Another factor that may have an impact on student's performance is aptitude. Carroll (1991) reports that aptitude contains four sub-components, namely, phonetic coding ability, grammatical sensitivity, inductive language analytic ability and associative memory. Their descriptions can be expanded and their perspectives can be processed to SLA by using the four factors as described below.

Phonetic coding ability: It is the capacity for sound discrimination. It varies between students but this variation does not correlate with learning success.

Associative memory: Associative memory is the ability to make links or connections between stimuli and responses for instance, native language words and foreign language equivalents. Now a days associative memory is not so, important and the capacity to memorize more auditory complex material and the capacity to impose organization and structure on the material are more useful predictors of success (Antoniou, 1998).

Grammatical sensitivity: It is the ability to understand the contribution that words make in sentences. It emphasizes recognition of function, rather than explicit representation.

Inductive language analytic ability: It is the capability to examine corpus of language material and form this to notice and identify patterns of correspondence and relationships. Whether this involves an implicit or explicit rule representation.

Class, size, schedule, environment: Students can face difficulty in learning due to the factors related with internal classroom. Some of these factors are physical aspects. These can have negative or positive impact on student's ability to learn.

The physical aspects of a classroom are made up of temperature, size, timetable and acoustics of a classroom. If these factors are unsatisfactory then they could hinder students from proper learning. For instance, if a classroom is too warm or too cold students will face difficulty to concentrate. As for size, merging two classes into one, may have a very strong negative impact, in addition to the background noises of the classroom and its surrounding environment that may also have a bad influence on student's mood as supported by Hughes and Jones (2001). When there is a negative impact on student's mood then the learning facilities are no more favorable to study in.

Text books and exam systems: Exam systems could have their share of negative impact on quality performance of students as they often result in a huge amount of stress (Wang and Yeh, 2005). Many students today feel much pressured. Indicated that stress is a normal physical response to events that make you feel threatened. Suggested that standard exam systems are not adequate to determine intelligence, many highly intelligent people are poor thinkers and many people of average intelligence are skilled thinkers. The power of a car is separate from the way it is driven. The roughening of the surface is never ideal for academic advancement because it creates as a distance between two points rather than a straight line an arabesque, i.e., it makes us pause over what we are reading. It obstacles the way of arriving at knowledge if one arrives at all.

Learning facilities and technology: Regarding the fact that the world is in a digital age, technology has taken centre the stage in virtually every human endeavor. Technology has revolutionized the ways human think and act. As a result, every country has tried to embrace it in their educational organization for proper positioning. Since, education holds the key to national development and to be essential, learning facilities must be placed in a greater pedestal.

Technological facilities are tools, equipments and gadgets used for systematic application of knowledge to heighten classroom learning and teaching they include: computers, interactive videos, power point projectors, software package, network hardware, cellular phone, satellite system, internet and other communication devices used in transmitting receiving and retrieving information (Ololube, 2011).

The importance of teacher education cannot be over emphasized. This is because lecturers play a critical role in any education system no education can rise above the quality of its professors. A part from this, university leaders are expected to ensure that the instruments are properly used and are kept in the right condition for use at all times. This calls for institutional leaders to supervise the activities of lecturers with regards to the deployment of technology in classroom instruction. Such leaders must be versatile in the utilization of technology in classrooms (Cakir, 2012). 


\section{MATERIALS AND METHODS}

The given data and statistical analysis are collected in January, 2018 from eighty students after providing them with clear knowledge about the nature of Factors Affecting Student's Performance, hence, forth (FASP). For the purpose of this study, tables, charts and SPSS were used to analyze the data that have been collected from students.

Research design: A survey (FASP) has been applied on sample of 80 students. Questionnaire in Appendix 1 and 2. The nature of questionnaire is which of the external and internal factors have a negative impact on student's performance and which have a positive contribution to theirs.

The answers of the questionnaire are typical answers (Strongly agree, agree, disagree and strongly disagree). Each answer represents a level of agreement with the statement; (A) Stands for the highest level of agreement while (B) represents a specific level of agreement and so, on for $C \& D$ in terms of disagreement. For this sake, ANOVA, Histograms and Microsoft Excel program have been used to analyze the collected data.

Participants: The participants of research are undergraduate students in the English Department, College of Arts, University of Kufa (evening study). A number of 80 students ranging from (19)-(30) or more have been randomly subjected to the survey of research. Twenty students (10 males and 10 females) are freshmen and the same number and is also followed with the year subject.

\section{RESULTS AND DISCUSSION}

The data collected from the questionnaire are converted to numbers and percentage as in Table 1. The data are divided according to student's age and gender and then converted to percentage for each. Statistical analysis has been applied on data to investigate the frequency and differences in answers.

\section{External factors:}

Extracurricular activities: The presented table shows the students who are more willing to count on the academic activities to heighten their scores. It can be seen that both genders $(42.5 \%)$ have equally scored for strongly agree with a slight margin of advantage when it comes to females as $(52.5 \%)$ of them choose agree for $(47.5 \%)$ of males. One male student has made up his mind to strongly disagree with the statement about the positive impact of the activities. All of first year female students, second year female students and fourth year male students have equally agreed with the statement $(70 \%)$. Third year female students scored the highest scores when $(80 \%)$ of them strongly agreed with the statement (Table 2 and Fig. 1).

Family problems: Table 3 shows that both genders are having similar level of suffering, (42.5\%) of both genders selected strongly agree on the other hand more females $(42.5 \%)$ agreed on the negative impact than males $(35 \%)$ concerning the family problems. Both of second year female students and fourth year male students have scored the same agreement $(70 \%)$ on the

Table 1: Scores acquired from student's questionnaire in general

\begin{tabular}{|c|c|c|c|c|}
\hline A-External factors & Strongly agree & Agree & Disagree & Strongly disagree \\
\hline Extracurricular activities & $34(42.5 \%)$ & $40(50 \%)$ & $5(6.3 \%)$ & $1(1.3 \%)$ \\
\hline Family problems & $34(42.5 \%)$ & $31(38.8 \%)$ & $11(13.8 \%)$ & $4(5 \%)$ \\
\hline Work and financial & $24(30 \%)$ & $30(37.5 \%)$ & $21(26.3 \%)$ & $5(6.3 \%)$ \\
\hline Social and others & $16(20 \%)$ & $34(42.5 \%)$ & $21(26.3 \%)$ & $9(11.3 \%)$ \\
\hline \multicolumn{5}{|l|}{ B-Internal factors } \\
\hline Competence and aptitude & $38(47.5 \%)$ & $36(45 \%)$ & $6(7.5 \%)$ & \\
\hline Class: schedule, size, environment & $23(28.8 \%)$ & $38(47.5 \%)$ & $12(15 \%)$ & $7(8.8 \%)$ \\
\hline Text books and exams system & $35(43.8 \%)$ & $32(40 \%)$ & $8(10 \%)$ & $5(6.3 \%)$ \\
\hline Learning facilities and technology & $45(56.3 \%)$ & $20(25 \%)$ & $9(11.3 \%)$ & $6(7.5 \%)$ \\
\hline
\end{tabular}

Table 2: Scores acquired from student's questionnaire (F: Female and M: Male)

\begin{tabular}{lcccc}
\hline Question No. & Strongly agree & Agree & Disagree & Strongly disagree \\
\hline First year F & $2(20 \%)$ & $7(70 \%)$ & 0 & $1(10 \%)$ \\
First year M & $4(40 \%)$ & $6(60 \%)$ & 0 & 0 \\
Second year F & $3(30 \%)$ & $7(70 \%)$ & 0 & 0 \\
Second year M & $6(60 \%)$ & $1(10 \%)$ & $3(30 \%)$ & 0 \\
Third year F & $8(80 \%)$ & $2(20 \%)$ & 0 & 0 \\
Third year M & $5(50 \%)$ & $5(50 \%)$ & 0 & 0 \\
Fourth year F & $4(40 \%)$ & $5(50 \%)$ & $1(10 \%)$ & 0 \\
Fourth year M & $2(20 \%)$ & $7(70 \%)$ & $1(10 \%)$ & 0 \\
Total F (N-40) & $17(42.5 \%)$ & $21(52.5 \%)$ & $1(2.5 \%)$ & $1(2.5 \%)$ \\
Total M (N-40) & $17(42.5 \%)$ & $19(47 . \%)$ & $4(4 \%)$ & 0 \\
Total (N-80) & $34(42.5 \%)$ & $40(50 \%)$ & $5(6.3 \%)$ & $1(1.3 \%)$ \\
\hline
\end{tabular}


The Soc. Sci., 14 (4): 155-168, 2019

Table 3: Scores acquired from student's questionnaire (F: Female and M: Male)

\begin{tabular}{lcccc}
\hline Question No. 2 & Strongly agree & Agree & Disagree & Strongly disagree \\
\hline First year F & $2(20 \%)$ & $6(60 \%)$ & $1(10 \%)$ & $1(10 \%)$ \\
First year M & $7(70 \%)$ & $2(20 \%)$ & $1(10 \%)$ & 0 \\
Second year F & $2(20 \%)$ & $7(70 \%)$ & $1(10 \%)$ & 0 \\
Second year M & $6(60 \%)$ & $1(10 \%)$ & $3(30 \%)$ & 0 \\
Third year F & $6(60 \%)$ & $2(20 \%)$ & $2(20 \%)$ & 0 \\
Third year M & $5(50 \%)$ & $2(20)$ & $1(10 \%)$ & $2(20 \%)$ \\
Fourth year F & $7(70 \%)$ & $2(20 \%)$ & $1(10 \%)$ & 0 \\
Fourth year M & $2(20 \%)$ & $7(70 \%)$ & $1(10 \%)$ & 0 \\
Total F (40) & $17(42.5 \%)$ & $17(42.5 \%)$ & $7(10 \%)$ & $2(5 \%)$ \\
Total M (40) & $17(42.5 \%)$ & $14(35 \%)$ & $11(13.8 \%)$ & $2(5 \%)$ \\
Total $(80)$ & $34(42.5)$ & $31(38.8 \%)$ & & $4(5 \%)$ \\
\hline
\end{tabular}

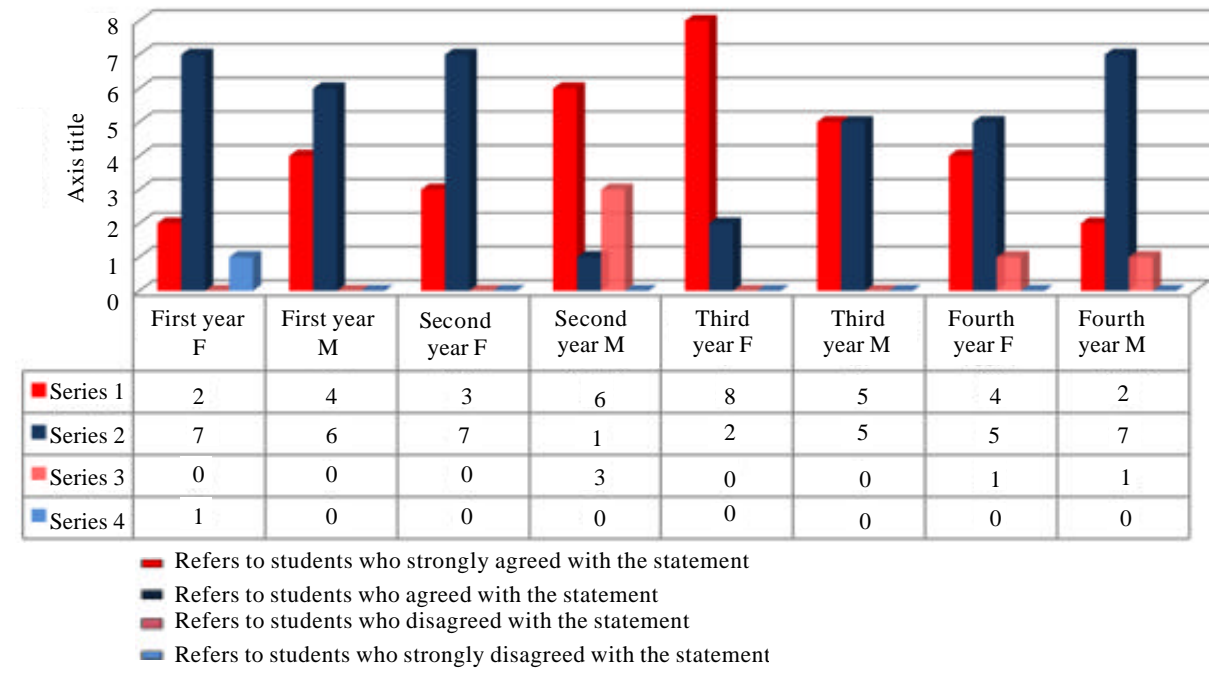

Fig. 1: Extracurricular activities

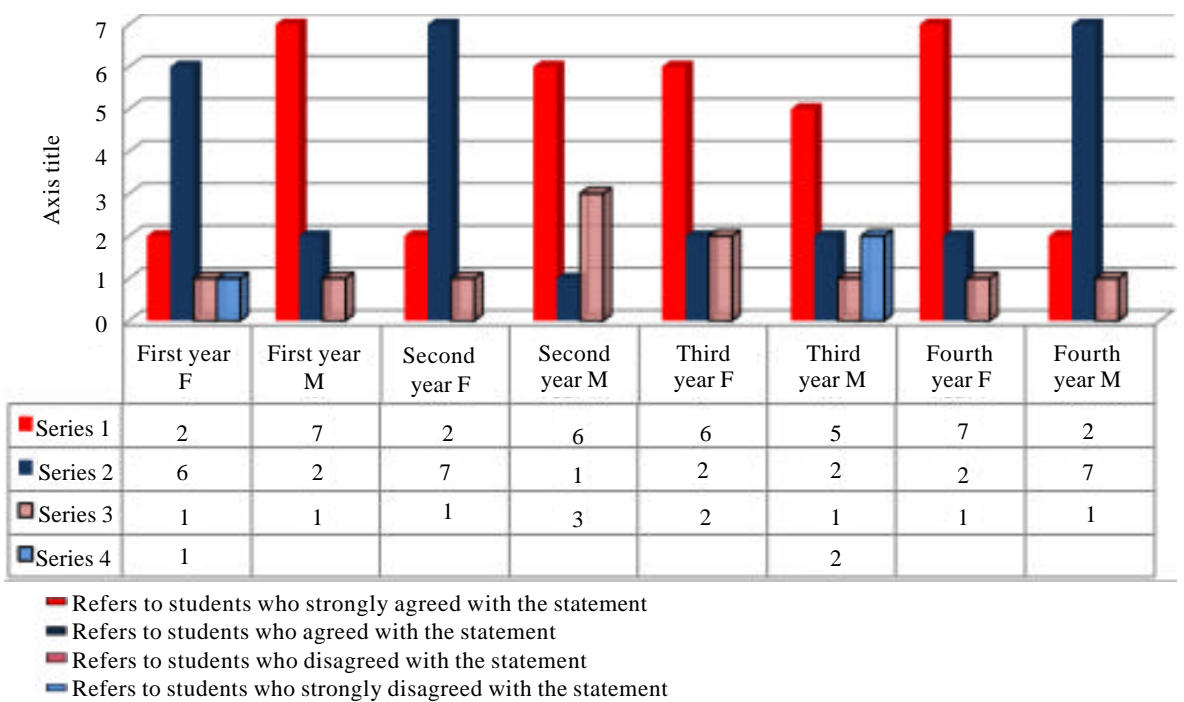

Fig. 2: Family problems

other side all stages have equal agreement concerning their agreement or strongly agreement with the statement (Fig. 2).
Work and financial situation: This table indicates that work and financial have a significant effect on student's overall academic achievement, especially, on males. 
The Soc. Sci., 14 (4): 155-168, 2019

Table 4: Scores acquired from student's questionnaire (F: Female and M: Male)

\begin{tabular}{lcccc}
\hline Question No. 3 & Strongly agree & Agree & Disagree & Strongly disagree \\
\hline First year F & $2(20 \%)$ & $5(50 \%)$ & $2(2 \%)$ & $1(10 \%)$ \\
First year M & $4(40 \%)$ & $4(40 \%)$ & $2(20 \%)$ & 0 \\
Second year F & 0 & $4(40 \%)$ & $5(50 \%)$ & $1(10 \%)$ \\
Second year M & $3(30 \%)$ & $4(40 \%)$ & $3(30 \%)$ & 0 \\
Third year F & $3(30 \%)$ & $2(20 \%)$ & $5(50 \%)$ & 0 \\
Third year M & $6(60 \%)$ & $2(20 \%)$ & $1(10 \%)$ & $1(10 \%)$ \\
Fourth year F & $2(20 \%)$ & $5(50 \%)$ & $2(20 \%)$ & $1(10 \%)$ \\
Fourth year M & $4(40 \%)$ & $4(40 \%)$ & $1(10 \%)$ & $1(10 \%)$ \\
Total F (40) & $7(17.5 \%)$ & $16(40 \%)$ & $14(35 \%)$ & $3(7.5 \%)$ \\
Total M (40) & $17(42.5 \%)$ & $14(35 \%)$ & $7(17.5 \%)$ & $2(5 \%)$ \\
Total $(80)$ & $24(30 \%)$ & $30(37.5 \%)$ & $21(26.3 \%)$ & $5(6.3 \%)$ \\
\hline
\end{tabular}

Table 5: Scores acquired from student's questionnaire (F: Female and M: Male)

\begin{tabular}{lcccc}
\hline Question No. & Strongly agree & Agree & Disagree & Strongly disagree \\
\hline First year F & $4(40 \%)$ & $3(30 \%)$ & $1(10 \%)$ & $2(20 \%)$ \\
First year M & $4(40 \%)$ & $3(30 \%)$ & $3(30 \%)$ & 0 \\
Second year F & $4(40 \%)$ & $4(40 \%)$ & $1(10 \%)$ & $1(10 \%)$ \\
Second year M & 0 & $4(40 \%)$ & $5(50 \%)$ & $1(10 \%)$ \\
Third year F & $3(30 \%)$ & $7(70 \%)$ & 0 & 0 \\
Third year M & $1(10 \%)$ & $4(40 \%)$ & $4(40 \%)$ & $1(10 \%)$ \\
Fourth year F & 0 & $4(40 \%)$ & $2(20 \%)$ & $4(40 \%)$ \\
Fourth year M & 0 & $5(50 \%)$ & $5(50 \%)$ & 0 \\
Total F $(40)$ & $11(27.5 \%)$ & $18(45 \%)$ & $4(10 \%)$ & $7(17.5 \%)$ \\
Total M (40) & $5(12.5 \%)$ & $16(40 \%)$ & $17(42.5 \%)$ & $2(5 \%)$ \\
Total $(80)$ & $16(20 \%)$ & $34(42.5 \%)$ & $21(26.3 \%)$ & $9(11.3)$ \\
\hline
\end{tabular}

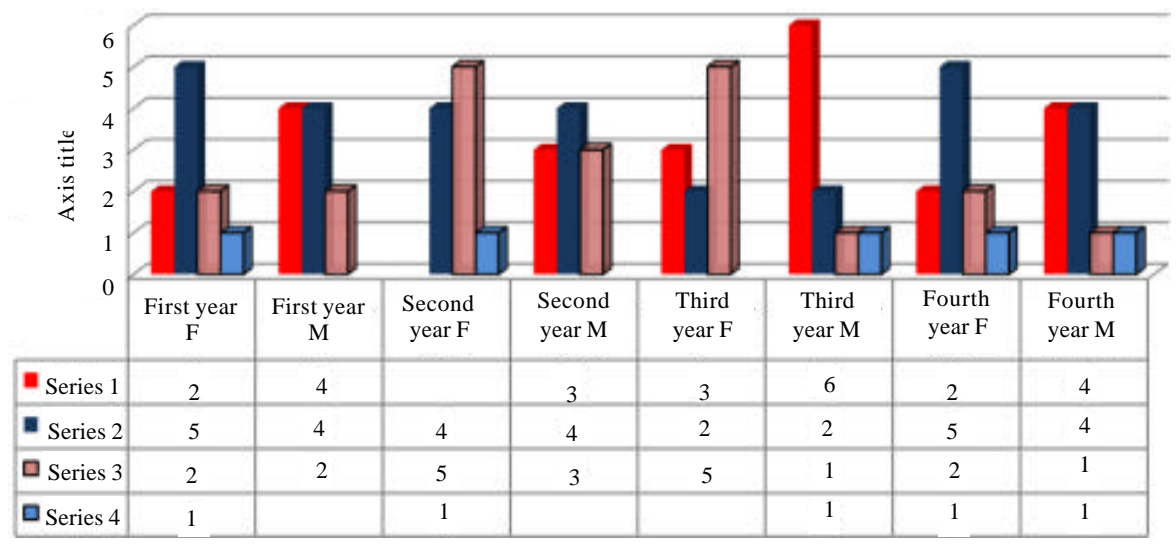

\footnotetext{
- Refers to students who strongly agreed with the statement

- Refers to students who agreed with the statement

- Refers to students who disagreed with the statement

- Refers to students who strongly disagreed with the statement
}

Fig. 3: Work and financial

$(42.5 \%)$ of males have proclaimed that this factor has a huge negative impact on their learning, compared to only $17.5 \%$ of females. It also displays that females (double in numbers) have slightly rejected the statement about the noxious impact of this aspect. This table illustrates a big difference in the answers of third stage students while $(60 \%)$ of males have strongly agreed with the negative impact of the work and financial factor $(50 \%)$ of females have disagreed with the statement. First year male students, second year male students and fourth year students recorded $(40 \%)$ of agreement (Table 4 and Fig. 3).

Social and other problems: The above Table 5 proves that social and other problems factor have affected mostly females from all the four stages $(27.5 \%)$ of them have been highly influenced and slightly suffered (45\%) in comparison with males whom the indicator reflects a rapid 


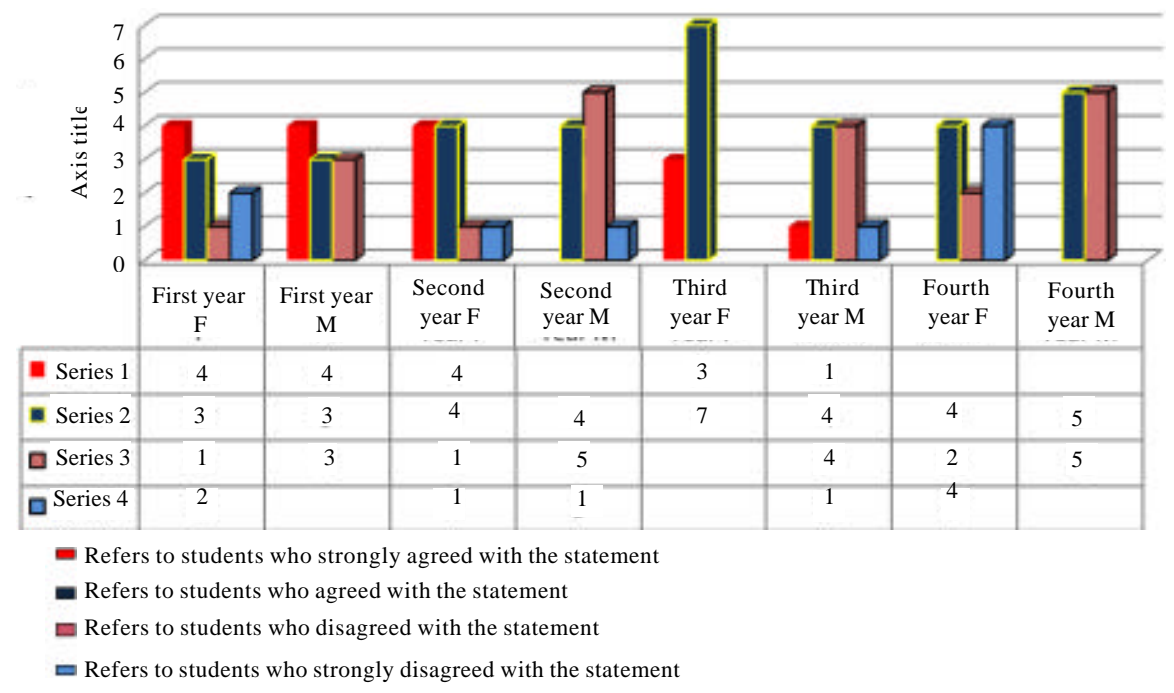

Fig. 4: Social and others

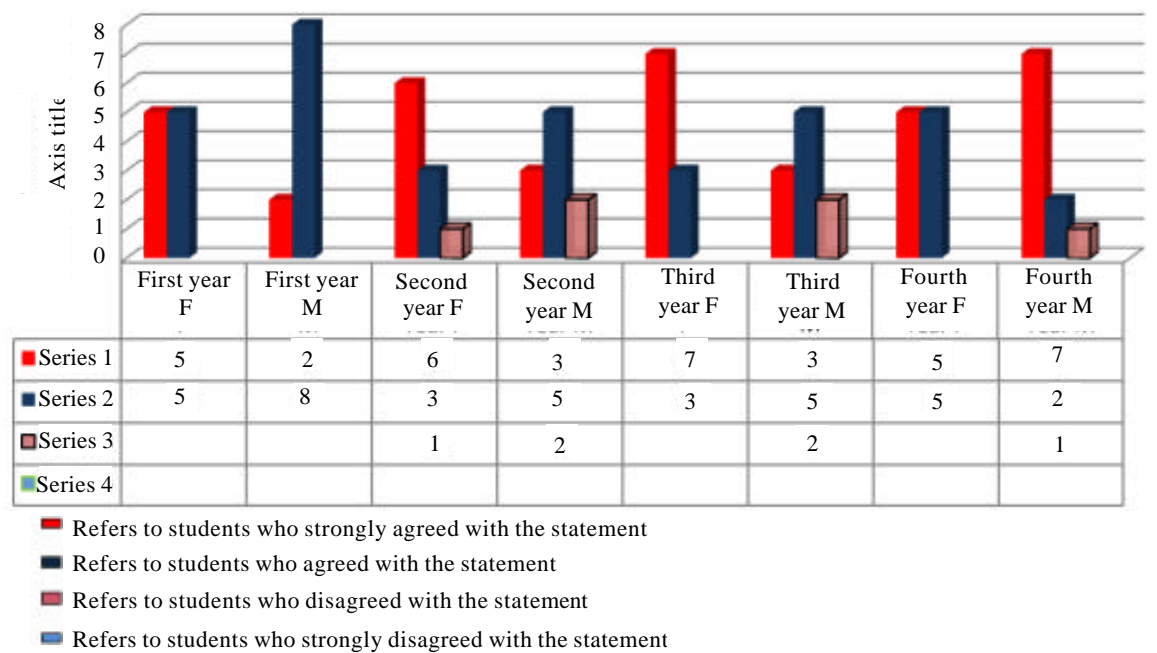

Fig. 5: Competence and aptitude

decrease with only $(12.5 \%)$ of them have been heavily affected and gradual decrease (40\%) when it comes to the slight impact made by this redounding. Third year female students seem to be affected by the social factor $(70 \%)$, compared to their peers. The other three stages have nearly the same answers with only fourth year male students have slight increase in agreement and disagreement with social and other problems factor $(50 \%)$ (Fig. 4).

\section{Internal factors:}

Student's competence and aptitude: It can be seen that there is a high tendency from students towards agreeing that competence and aptitude are the magnificent backers of one's academic progress with more females $(57.5 \%)$ strongly counting on competence as the sole factor for their procession, bear comparison with only $(37.5 \%)$ of males. There is an inclination for males not to regard competence as the only factor they might need for their advancement when $(12.5 \%)$ of them have made up their mind to disagree (Table 6 and Fig. 5).

Class: Schedule, size, environment: The above table demonstrates that females $(37.5 \%)$ have greater concern and pay more attention to their surrounding than men $(20 \%)$ do. This is related to their psychology as they value environmental concern as more important than men do and see environmentalism as important to escalate their skills because it gives them more relief as supported. First year female students, second year female students 
The Soc. Sci., 14 (4): 155-168, 2019

Table 6: Scores acquired from student's questionnaire (F: female and M: male)

\begin{tabular}{lcccc}
\hline Question No. & Strongly agree & Agree & Disagree & Strongly disagree \\
\hline First year F & $5(50 \%)$ & $5(50 \%$ & 0 & 0 \\
First year M & $2(20 \%)$ & $8(80 \%)$ & 0 & 0 \\
Second year F & $6(60 \%)$ & $3(30 \%)$ & $1(10 \%$ & 0 \\
Second year M & $3(30 \%)$ & $5(50 \%)$ & $2(20 \%)$ & 0 \\
Third year F & $7(70 \%)$ & $3(30 \%)$ & 0 & 0 \\
Third year M & $3(30 \%)$ & $5(50 \%)$ & 0 & 0 \\
Fourth year F & $5(50 \%)$ & $5(50 \%)$ & $1(10 \%)$ & 0 \\
Fourth year M & $7(70 \%)$ & $2(20 \%)$ & $1(2.5 \%)$ & 0 \\
Total F (40) & $23(57.5 \%)$ & $16(40 \%)$ & $5(12.5 \%)$ & 0 \\
Total M (40) & $15(37.5 \%)$ & $20(50 \%)$ & $6(7.5 \%)$ & 0 \\
Total $(80)$ & $38(47.5 \%)$ & $36(45 \%)$ & & 0 \\
\hline
\end{tabular}

Table 7: Scores acquired from student's questionnaire (F: female and M: male)

\begin{tabular}{lcccc}
\hline Question No. 2 & Strongly agree & Agree & Disagree & Strongly disagree \\
\hline First year F & $4(40 \%)$ & $2(20 \%)$ & $3(30 \%)$ & $1(10 \%)$ \\
First year M & $3(30 \%)$ & $6(60 \%)$ & 0 & $1(10 \%)$ \\
Second year F & $4(40 \%)$ & $3(30 \%)$ & $3(30 \%)$ & 0 \\
Second year M & $1(10 \%)$ & $5(50 \%)$ & $3(30 \%)$ & $1(10 \%)$ \\
Third year F & $4(40 \%)$ & $6(60 \%)$ & 0 & 0 \\
Third year M & $2(20 \%)$ & $5(50 \%)$ & $1(10 \%)$ & $2(20 \%)$ \\
Fourth year F & $3(30 \%)$ & $6(60 \%)$ & $2(20 \%)$ & $1(10 \%)$ \\
Fourth year M & $2(20 \%)$ & $5(50 \%)$ & $6(15 \%)$ & $1(10 \%)$ \\
Total F (40) & $15(37.5 \%)$ & $17(42.5 \%)$ & $6(15 \%)$ & $2(5 \%)$ \\
Total M (40) & $8(20 \%)$ & $21(52.5 \%)$ & $12(15 \%)$ & $5(12.5 \%)$ \\
Total $(80)$ & $23(28.8 \%)$ & $38(47.5 \%)$ & & $7(8.8 \%)$ \\
\hline
\end{tabular}

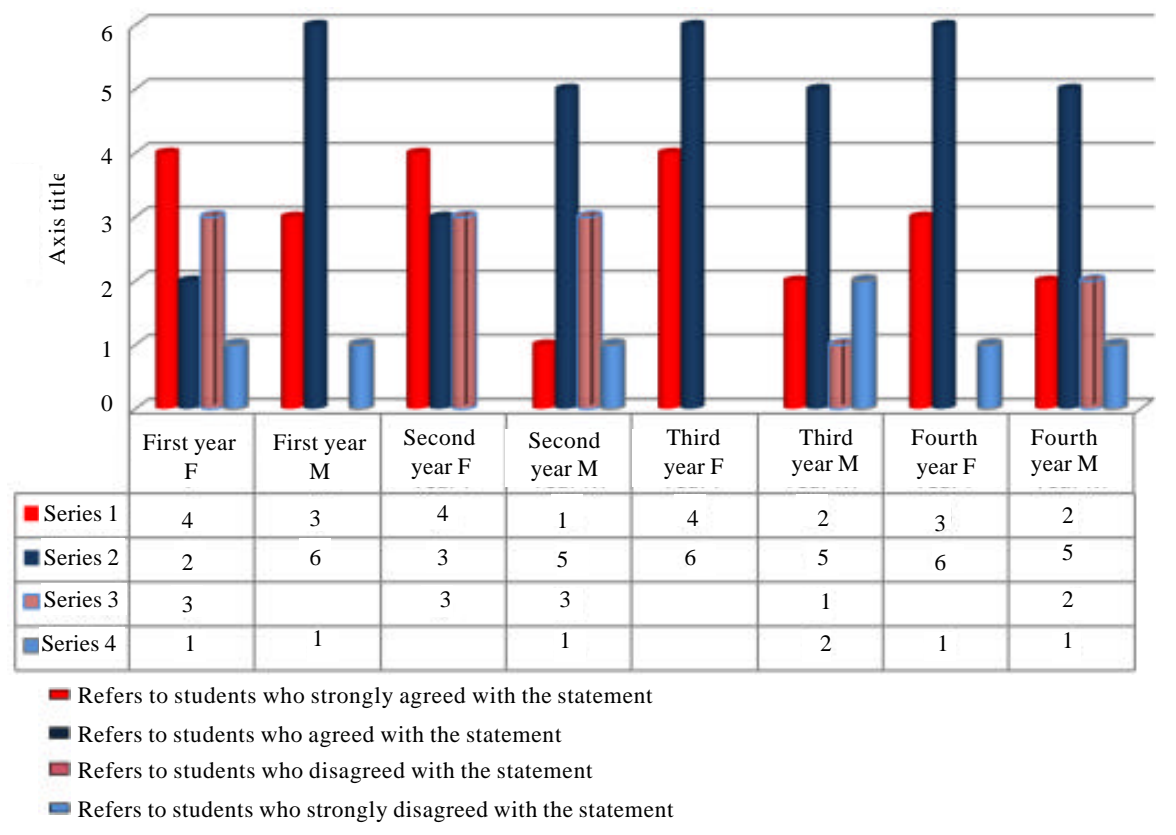

Fig. 6: Class: size, schedule, environment

and third year female students have strongly agreed $(40 \%)$ with the statement about the impact of class: size, schedule and environment factor. Third year male students and fourth year male students displayed same percentage of agreement $(50 \%)$ in comparison with $(60 \%)$ of female students of the same stages (Table 7 and Fig. 6).
Text books and exam systems: Table 8 displays that there is a balance in the answers of both genders when it comes to agreeing on the statement with a regard to its two variables. The $50 \%$ of females set their mind to strongly agree while $37.5 \%$ of them chose agree compared to $37.5 \%$ and $42.5 \%$ of males, respectively. It is worth mentioning that answers of freshman students are in a rapid 
The Soc. Sci., 14 (4): 155-168, 2019

Table 8: Text books and exam systems answers

\begin{tabular}{lcccc}
\hline Question No. 3 & Strongly agree & Agree & Disagree & Strongly disagree \\
\hline First year F & $5(50 \%)$ & $2(20 \%)$ & 0 & $3(30 \%)$ \\
First year M & $8(80 \%)$ & $1(10 \%)$ & $1(10 \%)$ & 0 \\
Second year F & $6(60 \%)$ & $3(30 \%)$ & $1(10 \%)$ & 0 \\
Second year M & $2(20 \%)$ & $6(60 \%)$ & $2(20 \%)$ & 0 \\
Third year F & $7(70 \%)$ & $3(30 \%)$ & 0 & 0 \\
Third year M & $3(30 \%)$ & $5(50 \%)$ & $2(20 \%)$ & 0 \\
Fourth year F & $2(20 \%)$ & $7(70 \%)$ & $1(10 \%)$ & 0 \\
Fourth year M & $2(20 \%)$ & $5(50 \%)$ & $2(20 \%)$ & $1(10 \%)$ \\
Total F (40) & $20(50 \%)$ & $15(37.5 \%)$ & $1(2.5 \%)$ & $4(10 \%)$ \\
Total M (40) & $15(37.5 \%)$ & $17(42.5 \%)$ & $7(17.5 \%)$ & $1(2.5 \%)$ \\
Total $(80)$ & $35(43.8 \%)$ & $32(40 \%)$ & $8(10 \%)$ & $5(6.3 \%)$ \\
\hline
\end{tabular}

Table 9: Scores acquired from student's questionnaire (F: Female and M: Male)

\begin{tabular}{lcclc}
\hline Question No. & Strongly agree & Agree & Disagree & Strongly disagree \\
\hline First year F & $6(60 \%)$ & $3(30 \%)$ & 0 & $1(10 \%)$ \\
First year M & $6(60 \%)$ & $3(30 \%)$ & $1(10 \%)$ & 0 \\
Second year F & $4(40 \%)$ & $4(40 \%)$ & 0 & $2(20 \%)$ \\
Second year M & $8(80 \%)$ & $1(10 \%)$ & 0 & $1(10 \%)$ \\
Third year F & $6(60 \%)$ & $2(20 \%)$ & $1(10 \%)$ & $1(10 \%)$ \\
Third year M & $8(80 \%)$ & $1(10 \%)$ & $1(10 \%)$ & 0 \\
Fourth year F & $4(40 \%)$ & $1(10 \%)$ & $5(50 \%)$ & 0 \\
Fourth year M & $3(30 \%)$ & $5(50 \%)$ & $1(10 \%)$ & $1(10 \%)$ \\
Total F (40) & $20(50 \%)$ & $10(25 \%)$ & $6(15 \%)$ & $4(10 \%)$ \\
Total M $(40)$ & $25(62.5 \%)$ & $10(25 \%)$ & $3(7.5 \%)$ & $2(5 \%)$ \\
Total $(80)$ & $45(56.3 \%)$ & $20(25 \%)$ & $9(11.3 \%)$ & $6(7.5 \%)$ \\
\hline
\end{tabular}

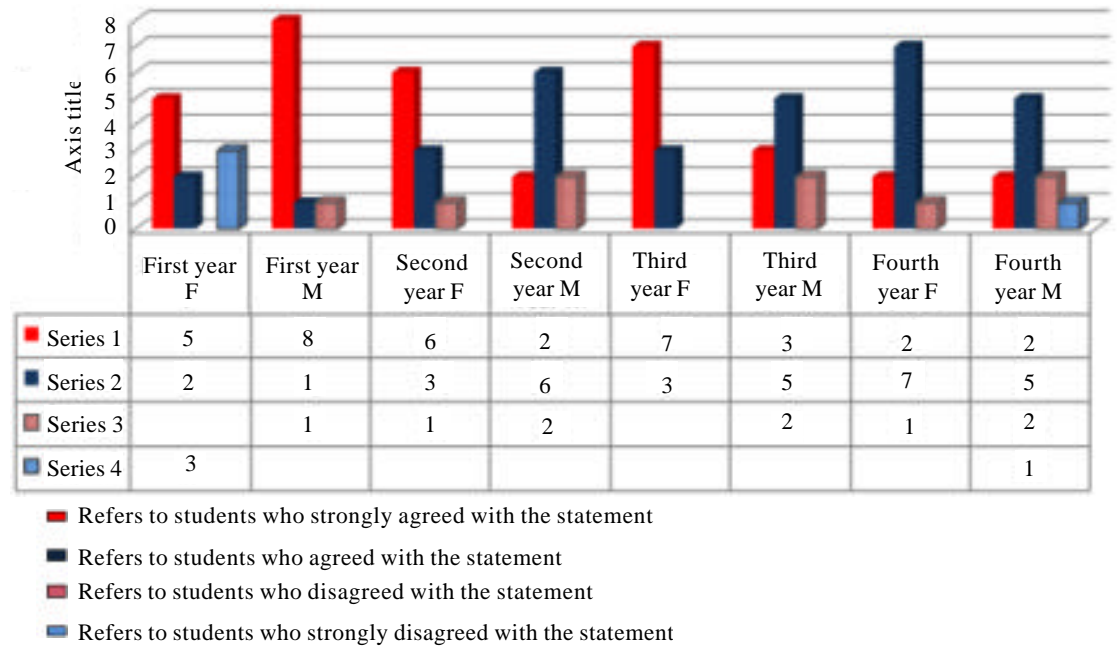

Fig. 7: Text books and exam systems

changing, $80 \%$ of males strongly agreed in contrast with only $50 \%$ of females. Also $30 \%$ of females chose to strongly disagree with this factor while nothing to mention concerning males about this choice. This can confirm that females are more committed to rules by their nature as supported by Marsden et al. (1993) (Fig. 7).

Learning facilities and technology: Statistics of learning facilities and technology confirm that males are more willing and more confident in the systematic application of knowledge in classrooms than females. In general, $62 \%$ of males strongly agree that learning and technological facilities would definitely have a prime positive impact on their academic experience (Table 9). This called for further investigation as seen in Table 10 to determine which age would be more beneficial of this application. Based on the results from Table 9, it is seen that the age between (20-23) have a tendency to reap benefits from the technological environment. There are $40 \%$ male students aged between (20-23) set to choose strongly agree to only $17.5 \%$ of females. This percentage shows beyond doubt 
The Soc. Sci., 14 (4): 155-168, 2019

Table 10: Scores acquired from student's questionnaire

\begin{tabular}{lcrr}
\hline Female students data & Frequency & Percent & Cumulative (\%) \\
\hline 19 strongly agree female & 2 & 5.0 & 5.0 \\
19 agree female & 1 & 2.5 & 7.5 \\
19 strongly disagree female & 1 & 2.5 & 10.0 \\
$20-23$ strongly agree female & 7 & 17.5 & 27.5 \\
$20-23$ agree female & 5 & 12.5 & 40.0 \\
$20-23$ disagree female & 1 & 2.5 & 42.5 \\
$20-23$ strongly disagree female & 1 & 2.5 & 45.0 \\
$24-29$ strongly agree female & 6 & 15.0 & 60.0 \\
$24-29$ agree female & 1 & 2.5 & 62.5 \\
$24-29$ disagree female & 1 & 2.5 & 65.0 \\
$30-39$ strongly agree female & 5 & 12.5 & 77.5 \\
$30-39$ agree female & 3 & 7.5 & 85.0 \\
$30-39$ disagree female & 5 & 12.5 & 97.5 \\
$30-39$ strongly disagree female & 1 & 2.5 & 100.0 \\
Total & 40 & 100.0 & \\
Male students data & & & \\
19 strongly agree male & 1 & 2.5 & 2.5 \\
$20-23$ strongly agree male & 16 & 40.0 & \\
$20-23$ agree male & 3 & 7.5 & 5.5 \\
$20-23$ disagree male & 1 & 2.5 & 5.0 \\
$20-23$ strongly disagree male & 2 & 5.0 & 5.5 \\
$24-29$ strongly agree male & 4 & 10.0 & \\
$24-29$ agree male & 1 & 2.5 & \\
$30-39$ strongly agree male & 4 & 10.0 & \\
$30-39$ agree male & 6 & 15.0 & \\
$30-39$ disagree male & 40 & 5.0 & \\
Total & & 100.0 & \\
\end{tabular}

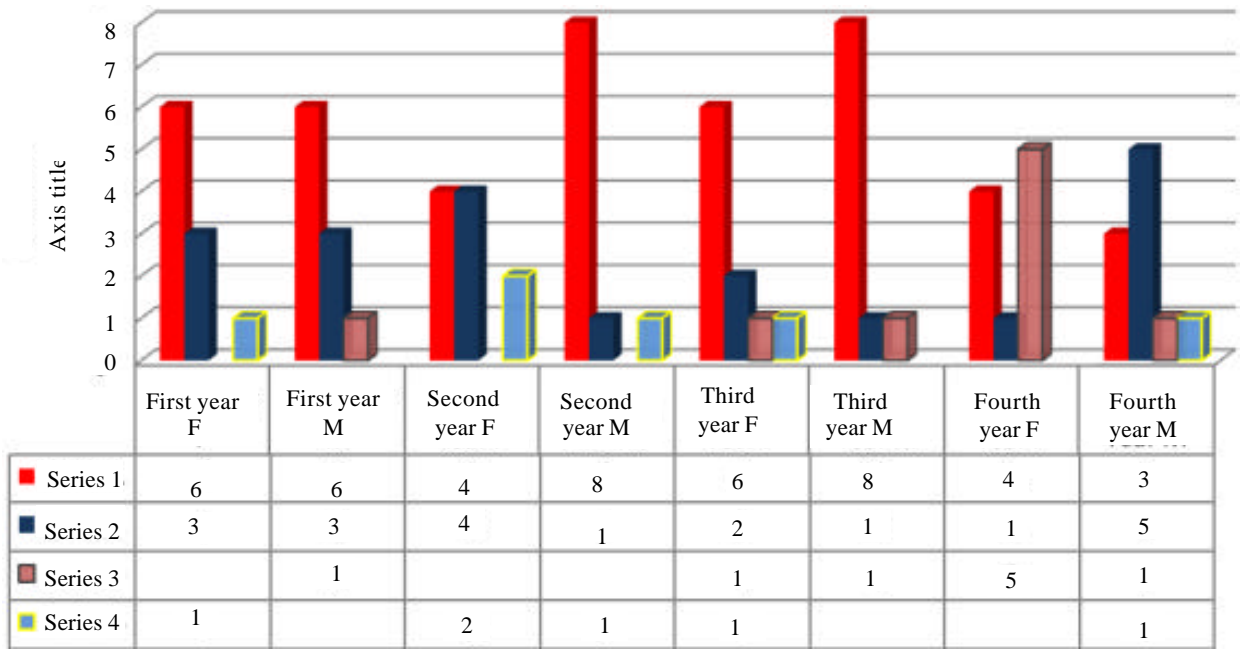

\footnotetext{
- Refers to students who strongly agreed with the statement

- Refers to students who agreed with the statement

- Refers to students who disagreed with the statement

- Refers to students who strongly disagreed with the statement
}

Fig. 8: Learning facilities and exam systems

that males more than preferable to be provided with this learning aspect. Another point is that students who are aged 30 or more tend to see that technological aspect brings nothing to their quality performance than the other ages. There are $12.5 \%$ of females of the age mentioned earlier chose to disagree. The below charts show the answers of female and male student's answers, respectively. (AgeTechGender) are randomly labeled for proceeding with the programme (Fig. 8-10). 


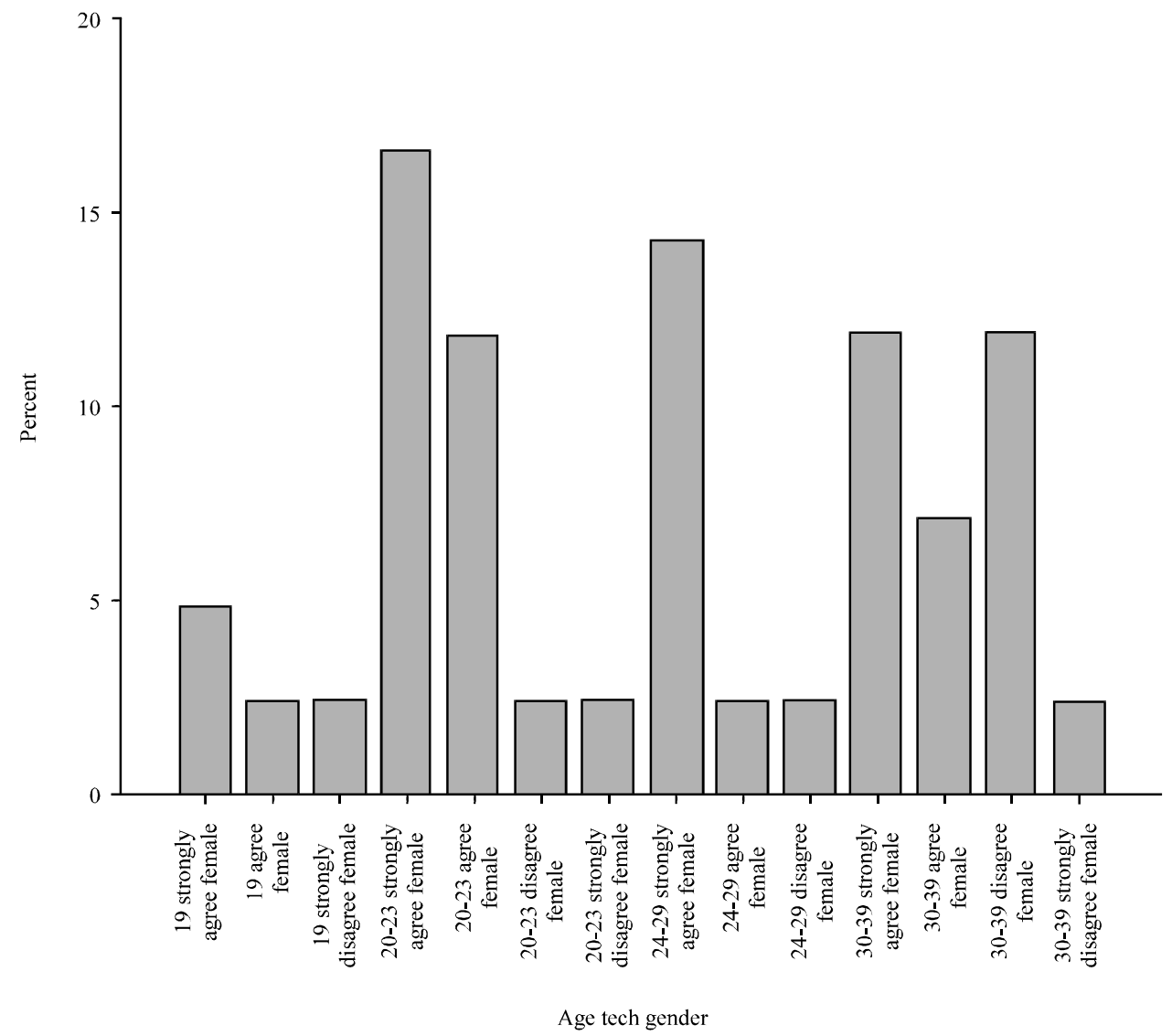

Fig. 9: The answers of female students

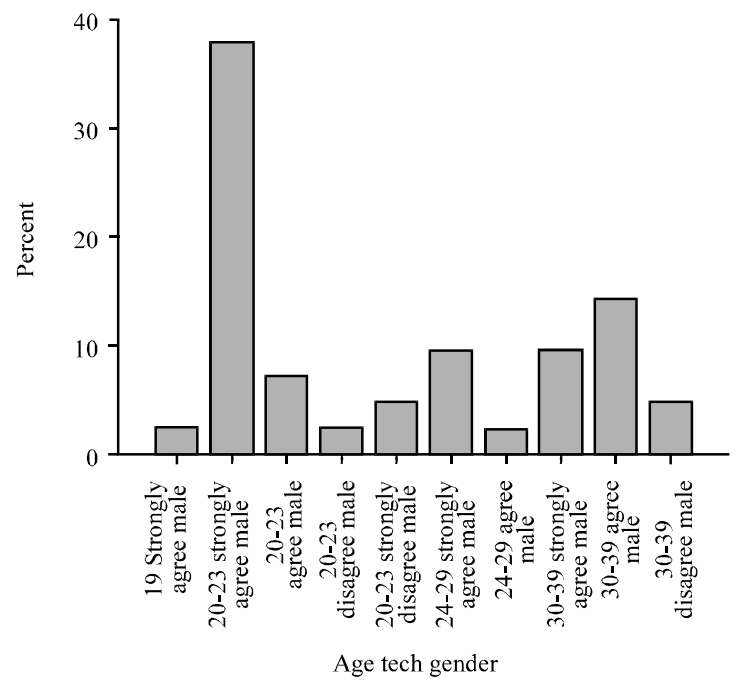

Fig. 10: The answers of male students

\section{CONCLUSION}

According to the results and their discussions, the study concluded the following: extracurricular activities can help heighten student's academic achievements as well as enriching the college experience. Family problems can highly affect students and reduce their performances.

Work and financial have a significant effect on student's overall academic performance besides the other characteristic factors like Socio-Economic Status (SES). Higher SES lead to higher performance of students in studies and vice versa (Hanes, 2008).

Social and other problems can have a slight influence on quality performance but they are easier to overcome. Competence and aptitude are remarkable predictors for student's academic performance. Schedule, size and environment can greatly contribute to poor learning process.

Most of the students are suffering from text books and exam systems factor these suffering results in poor academic performances. Learning facilities and technology as a factor has the biggest share of influence on student's academic performance as it holds the highest percentage of influence ever recorded in this study $(56.3 \%)$. Thus, the questions settled earlier of the research are logically answered. 
Suggestions for further research: The following suggestions could be investigated in further research: a study can be undertaken to measure the factors that contribute in both writing and speaking for students.

More research can be carried out to include different colleges from different universities to monitor the changing in factors affecting academic performance of students. Further research is needed to explore the problem on a large sample from more scattered geographical regions including other individual differences factors, parental education factors, university factors and most importantly the academic level of teachers factor.

\section{APPENDIX 1}

\section{Questionnaire}

\section{External factors}

A-Extracurricular activities:

1) Strongly agree

2) Agree

3) Disagree

4) Strongly disagree

B-Family problems:

1) Strongly agree

2) Agree

3) Disagree

4) Strongly disagree

C-Work and financial:

1) Strongly agree

2) Agree

3) Disagree

4) Strongly disagree

\section{D-Social and Other problems:}

1) Strongly agree

2) Agree

3) Disagree

4) Strongly disagree

Internal factors:

A-Student's competence and aptitude:

1) Strongly agree

2) Agree

3) Disagree

4) Strongly disagree

B-Class: Schedule, size, environment:

1) Strongly agree

2) Agree

3) Disagree

4) Strongly disagree
C-Text books and exam systems:

1) Strongly agree

2) Agree

3) Disagree

4) Strongly disagree

D-Learning facilities and technology:

1) Strongly agree

2) Agree

3) Disagree

4) Strongly disagree

\section{APPENDIX 2}

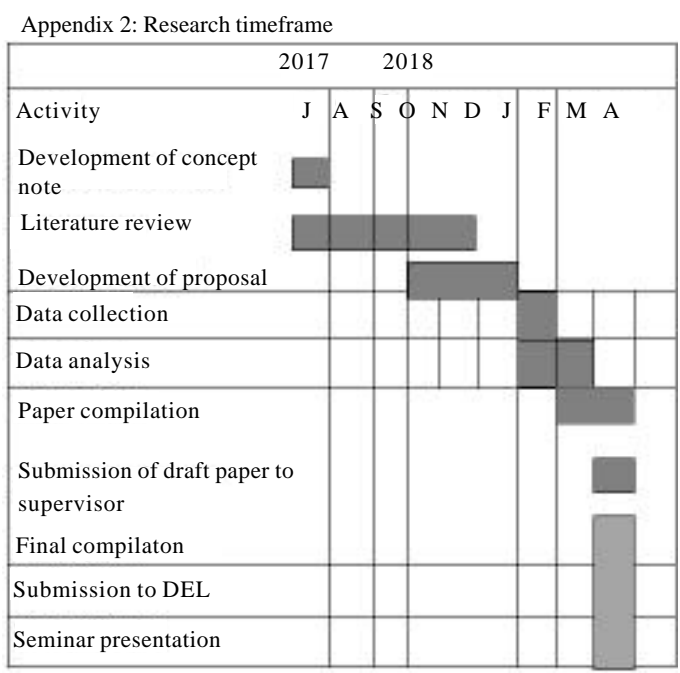

\section{REFERENCES}

Antoniou, G., 1998. Stratification for default logic variants. Intl. J. Intell. Syst., 13: 785-799.

Billingham, R.E. and N.L. Notebaert, 1993. Divorce and dating violence revisited: Multivariate analyses using Straus's conflict tactics subscores. Psychol. Rep., 73: 679-684.

Brown, L.L. and S. Kurpius, 1997. Psychosocial factors influencing academic persistence of American Indian college students. J. Coll. Stud. Dev., 38: 3-12.

Cakir, A., 2012. The use of the EPOSTL to foster teacher autonomy: ELT student teachers and teacher trainers views. Aust. J. Teach. Educ., 37: 1-16.

Caldas, S.J. and C. Bankston, 1997. Effect of school population socioeconomic status on individual academic achievement. J. Educ. Res., 90: 269-277.

Carroll, A.B., 1991. The pyramid of corporate social responsibility: Toward the moral management of organizational stakeholders. Bus. Horiz., 34: 39-48. 
Duke, N.K., 2000. For the rich it's richer: Print environments and experiences offered to first-grade students in very low- and very high-SES school districts. American Educational Research Journal, 37: 441-478.

Fagan, P.F. and R. Rector, 2000. The effects of divorce on America. World I., 15: 56-61.

Fantuzzo, J., E. Tighe and S. Childs, 2000. Family involvement questionnaire: A multivariate assessment of family participation in early childhood education. J. Educ. Psychol., 92: 367-376.

Furstenberg Jr. F.F. and M.E. Hughes, 1995. Social capital and successful development among at-risk youth. J. Marriage Family, 57: 580-592.

Goddard, R.D., 2003. Relational networks, social trust and norms: A social capital perspective on students' chances of academic success. Educ. Eval. Policy Anal., 25: 59-74.

Hanes, B.R., 2008. The exploration of socioeconomic status and student achievement at Beverly Elementary School. Ph.D Thesis, Marietta College, Marietta, Georgia.

Harb, N. and A. El-Shaarwi, 2006. Factors affecting student's performance. J. Educ., 82: 282-290.

Hughes, R. and D.M. Jones, 2001. The intrusiveness of sound: Laboratory findings and their implications for noise abatement. Noise Health, 4: 51-70.

Kirkup, J., 2008. Middle-class children resentful at being pushed to succeed. The Telegraph, London, England. https://www.telegraph.co.uk/ education/3330301/Middle-class-children-resentfulat-being-pushed-to-succeed-poll-shows.html
Marsden, P.V., A.L. Kalleberg and C.R. Cook, 1993. Gender differences in organizational commitment: Influences of work positions and family roles. Work Occupations, 20: 368-390.

Michael, S.O., 1998. Restructuring US higher education: discontinuation. Rev. Higher Educ., 21: 377-404.

Ololube, N.P., 2011. Blended Learning in Nigeria: Determining Student's Readiness and Faculty role in Advancing Technology in a Globalized Educational Development. In: Blended Learning Across Disciplines: Models for Implementation, Ololube, N.P. (Ed.). IGI Global, Pennsylvania, USA., pp: 190-207.

Parelius, R. J. and A.N. Parelius, 1987. Sociology of Education. Prentice Hall International, USA.,

Roberts, G.A., 2007. The effect of extracurricular activity participation on the relationship between parent involvement and academic performance in a sample of third grade children. Ph.D Thesis, The University of Texas at Austin, Austin, Texas.

Rouse, C.E. and L. Barrow, 2006. US Elementary and secondary schools: Equalizing opportunity or replicating the status quo?. Future Children, 16: 99-123.

Tsinidou, M., V. Gerogiannis and P. Fitsilis, 2010. Evaluation of the factors that determine quality in higher education: An empirical study. Qual. Assur. Educ., 18: 227-244.

Wang, H.F. and M.C. Yeh, 2005. Stress, coping and psychological health of vocational high school nursing students associated with a competitive entrance exam. J. Nurs. Res., 13: 106-116.

White, R.W. and T.F. White, 1995. Repression and the liberal state: The case of Northern Ireland, 1969-1972. J. Conflict Resolution, 39: 330-352. 